\title{
Racionalização energética de uma estação de pressurização de um perímetro irrigado
}

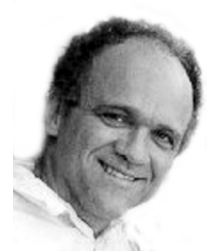

Delly Oliveira Filho ${ }^{1}$, Carlos A. Teixeira² \& Marcos C. Ribeiro ${ }^{3}$

1 DEA/UFV. Viçosa, MG. Fone: (31) 3899-1897. E-mail: delly@ufv.br (Foto)

2 DEA/UFV. Fone: (31) 3899-1930. E-mail: carlos@vicosa.ufv.br

${ }^{3}$ DEA/UFV. Fone: (31) 3899-1930. E-mail: mcaldeira@vicosa.ufv.br

Protocolo 7 - 20/1/2003 - Aprovado em 16/12/2003

\begin{abstract}
Resumo: Dentre as formas de se diminuir os custos de energia elétrica dos irrigantes e seus custos de produção, listam-se: (i) a adequação do bombeamento de água; (ii) a adequação de força motriz, e (iii) o gerenciamento do uso da água. $O$ experimento foi realizado no Perímetro Irrigado de Mirorós, localizado no município de lbipeba, Bahia. O estudo foi feito para a estação de pressurização 1 e analisados dois, de seus quatro conjuntos de motobombas. 0 processo de otimização do uso de energia adotado envolveu a adequação da bomba, do motor elétrico e a avaliação do conjunto motobomba. O potencial de economia de energia global, com a adequação do conjunto motobomba 1, foi de cerca de $8,75 \%$ e, para o conjunto 2, de $31,6 \%$. Observouse também que, quanto maior for o índice de carregamento, menor será o valor cobrado da água e, para tal, é necessário gerenciar o número de lotes em que se usa a irrigação simultaneamente.
\end{abstract}

Palavras-chave: racionalização do uso de energia, irrigação, conjunto motobomba

\section{Energy management of pumping station in an irrigated perimeter}

\begin{abstract}
In order to decrease the production costs of small farmers - the participants of irrigation district, the possibilities to save electrical energy are: (i) sizing the water pumping systems; (ii) adopt the electric motive power, and (iii) management of the water use. The experiment was conducted in the Miroros Irrigated Perimeter, located in Ibipeba, Bahia, Brazil. The study was done on the pressurization station 1, where two out of four motor pump sets were analyzed. The process of energy optimization used includes the pump and electric motor dimensioning and the evaluation of the pump-motor set. The global savings potential with the motor pump Set 1 was around $8.75 \%$ and for the Set 2 was around $31.6 \%$. It was observed as well, that the greater the load index (ratio between the actual load and the rated power) smaller would be the water charges. In order to achieve the desired savings in the water use management, measures are to be implemented to stimulate simultaneous water use by the farmers.
\end{abstract}

Key words: load management, irrigation, motor-pump-set

\section{INTRODUÇÃO}

Devido a crescente inserção do Brasil no cenário mundial, ocorrem mudanças no sentido de que os seus produtos sejam ainda mais competitivos, sendo a oferta de energia como um dos fatores mais importantes no contexto atual. As dificuldades energéticas no ano 2001, especialmente o racionamento de energia elétrica, constituíram um alerta quanto ao futuro da Nação, gerando questionamentos, como: até onde é compensador investir apenas em usinas de geração de energia, inundando milhares de hectares de terras agricultáveis, toneladas de carvão ou óleo, impactando e poluindo o meio ambiente? Tais questões são facilmente percebíveis, mas de difícil solução, cuja resposta poderá ser encontrada na racionalização do uso da energia resultando, inclusive, na ampliação da produção, no aumento dos benefícios sociais e da competitividade, além da minimização dos custos.

Os benefícios sociais provenientes da agricultura irrigada são imensos e, dentre eles, está a recolocação do homem no campo, para cuja fixação é necessário que as tarifas de energia sejam adequadas e, simultaneamente, haja racionalização do uso da energia elétrica; esta racionalização aumenta a rentabilidade da atividade rural contribuindo, portanto, para melhoria da qualidade de vida no campo. 
Comparando-se alguns sistemas de irrigação de lavouras que utilizam a energia elétrica para distribuição ou captação dos recursos hídricos, conclui-se que o custo da energia elétrica pode chegar a até 30\% do custo da produção (Bernardo, 1995).

Atualmente, quase a metade da população mundial depende de alimentos produzidos mediante a aplicação de irrigação. $\mathrm{O}$ contínuo crescimento da população mundial exige uma agricultura competitiva e tecnificada, que possibilite a produção de alimentos de melhor qualidade e em maior quantidade, sendo a irrigação uma excelente estratégia para o alcance desses objetivos.

No Brasil, como em outros países, a irrigação constitui um componente importante no setor produtivo agropecuário. A superfície produtiva agrícola sob sequeiro, em torno de 1.225 milhões de hectares, é responsável por 58\% da colheita total, enquanto a superfície agrícola irrigada, embora correspondendo a apenas $18 \%$ da área produtiva total, contribui com cerca de $42 \%$ do total colhido (Christofidis, 2002). Ressalta-se que, em 24 anos, a agricultura irrigada mundial aumentou de 190 milhões para 275 milhões de hectares, ou seja, $45 \%$; isto faz com que mais empresas invistam em tecnologia irrigada, aprimorando o setor com mais investimentos na eficiência de seus equipamentos.

O uso da água na agricultura representa, em nível global mundial, cerca de $70 \%$ de toda a água derivada de rios, lagos e mananciais subterrâneos, enquanto a indústria utiliza $23 \%$ e o abastecimento humano consome 7\%. Apesar do grande consumo de água, a irrigação representa a maneira mais eficiente e produtiva de se obter alimentos. Estima-se que, no futuro próximo, de metade a dois terços da produção de alimentos serão provenientes da agricultura irrigada (Santos, 1998).

Irrigar uma lavoura é uma prática que se confunde com a história do desenvolvimento e prosperidade econômica de um povo. A irrigação proporciona riqueza, pois garante aumento na produtividade e agrega valor aos produtos, além de contribuir para a resolução do problema da seca, permitindo cultivos durante o ano todo.

Um fato importante a ser registrado foi a mudança no perfil de expansão da área irrigada, a partir dos anos 80 . As dificuldades administrativas e os elevados custos de implantação de perímetros irrigados, sob coordenação governamental, favoreceram a implantação de projetos pela iniciativa privada. Essas mudanças implicam em maior abrangência territorial da área irrigada, com prioridades naturais para as regiões de maior potencial agrícola.

Nas estações de bombeamento de um perímetro irrigado estão associados diversos fatores, que contribuem para melhoria na integração do uso dos recursos físicos e para a racionalização do uso de energia, ou seja: (i) manutenção centralizada; (ii) uso de bombas e motores de maior potência e portanto de maior eficiência energética, e (iii) racionalização de investimentos em obras civis.

Se um sistema de irrigação não for bem operado, ocorrerá desperdício ou descontrole durante a irrigação, podendo sobrecarregar o conjunto motobomba, cuja finalidade é manter a vazão e a pressão da água, conforme planejado. Em um perímetro público irrigado é crescente o anseio dos irrigantes por uma conduta metodológica do uso da água e suas implicações.
A irrigação é fator de importância não apenas social e econômica mas, também, estratégica, para a Nação. O uso racional de energia na irrigação permite minimizar impactos ambientais e aumentar a atratividade da atividade agrícola. A produção de alimentos é importante econômica, social e estrategicamente, para o País.

Neste contexto, o objetivo geral do presente trabalho é racionalizar, energética e economicamente, uma estação de bombeamento do Perímetro Irrigado de Mirorós, no estado da Bahia. Os objetivos específicos são: (i) adequar o dimensionamento hidráulico às necessidades do perímetro irrigado; (ii) adequar o dimensionamento elétrico às necessidades do perímetro irrigado, e (iii) propor medidas de gerenciamento do uso do sistema de bombeamento visando à racionalização do uso de energia elétrica e hidráulica, para maximizar a economia de energia.

\section{MATERIAL E MÉTODOS}

A coleta de dados foi realizada no Perímetro Irrigado de Mirorós, administrado pelo Distrito de Irrigação do Perímetro Irrigado de Mirorós - DIPIM, em convênio com a Companhia de Desenvolvimento dos Vales do São Francisco e do Parnaíba (CODEVASF). O Perímetro Irrigado de Mirorós está localizado no município de Ibipeba, Bahia. A análise dos dados foi feita no Laboratório de Energia do Departamento de Engenharia Agrícola da Universidade Federal de Viçosa, MG.

A superfície do perímetro é de 2.166 ha irrigáveis por aspersão convencional e microaspersão e se abastece por um canal aberto, sendo parte da água distribuída entre empresários agrícolas e a outra parte captada por 5 estações de bombeamento, enviadas a mais de 200 pequenos produtores com áreas de aproximadamente 5 ha por lote. A área de estudo é a estação de pressurização 1 (EP1) que apresenta uma das maiores alturas manométricas e de maior custo de energia elétrica específico.

\section{Análise da adequação de bombas centrífugas atual}

O dimensionamento do conjunto motobomba foi feito utilizando-se análise das características de bombas e cálculos hidráulicos, conforme Figura 1.

A Figura 1A apresenta, para diversos diâmetros de rotor, o rendimento hidráulico em função da altura manométrica, que é a pressão desejada, e da vazão. A Figura 1B mostra a potência requerida no eixo, em função do diâmetro do rotor e vazão da bomba.

Na Figura 1A observa-se que a escolha da bomba e o diâmetro do rotor, do modelo e o fabricante, determinarão as características hidráulicas do projeto (vazão e altura manométrica total) e o rendimento da bomba, enquanto a Tabela 1 apresenta as características mecânicas e hidráulicas das bombas utilizadas na EP1.

Na Tabela 1 são apresentadas as características de vazão e pressão para as quatro bombas. De posse das informações de vazão e pressão (altura manométrica) requeridas, foi formado um banco de dados para determinação das características das bombas que melhor satisfaçam as exigências de projetos e dos parâmetros econômicos e de manejo do sistema. 

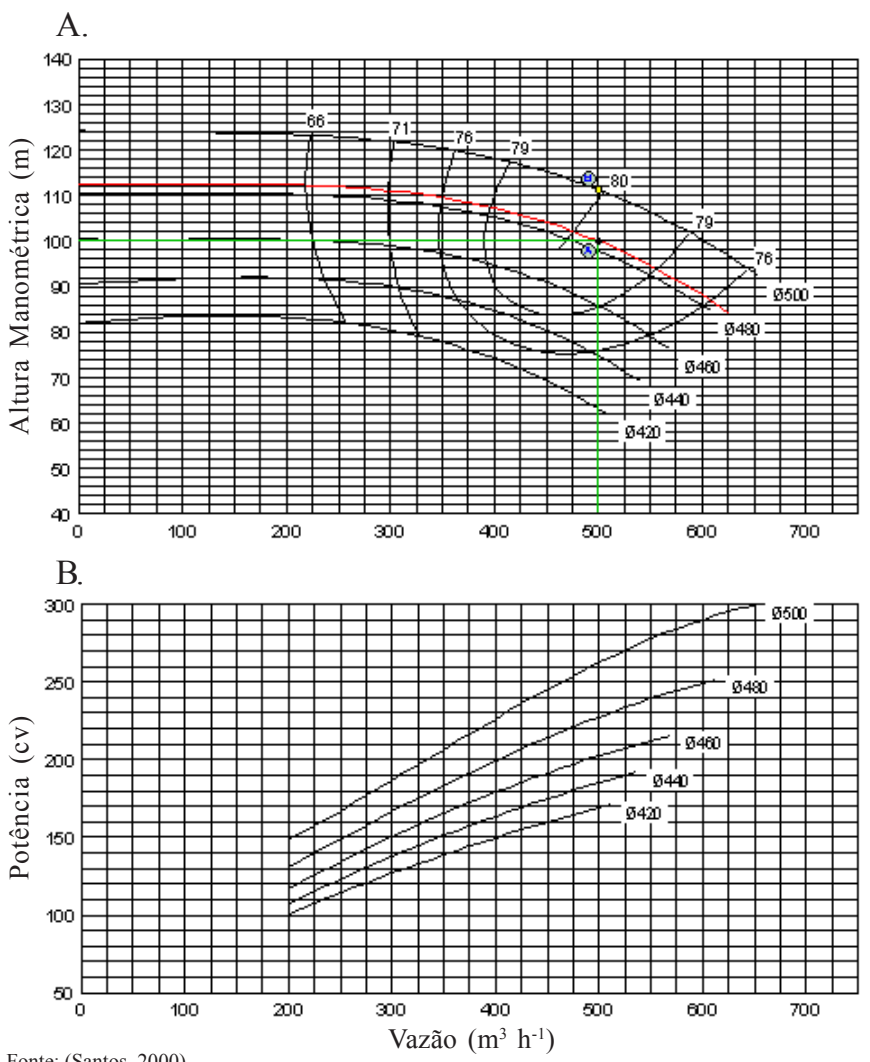

Figura 1. Curvas características típicas de bomba hidráulica

\section{Proposta para adequação de bombas centrífugas}

De acordo com Santos (2001) para a adequação de bombas centrífugas é importante que se faça a avaliação da vazão e da pressão. A escolha de cada uma das bombas centrífugas foi feita utilizando-se o programa computacional AgriBombas. O programa contém dados de cinco fabricantes de bombas (KSB, Sheneider, Mark Peerless, Imbil e EH) para diferentes rotações, podendo-se selecionar até dez bombas diferentes, que melhor otimizem a escolha (Santos, 2000; Campana, 2000). Este programa busca, dentre todas as bombas existentes em seu banco de dados, aquelas que melhor otimizem tecnicamente a situação em questão.

De posse da nova curva característica da bomba otimizada, esta foi comparada à característica da bomba em funcionamento e, em seguida, fez-se a análise econômica de vida útil para o investimento.

As opções para adequação das bombas centrífugas investigadas são:

a) bomba em uso versus bomba adequada à condição de carga

b) bomba em uso versus bomba adequada à condição de carga e otimizada.

\section{Análise do dimensionamento elétrico atual}

Foram analisados os quatro motores da estação de bombeamento EP1 e suas características elétricas estimadas, medindo-se a corrente elétrica em plena carga. Os motores elétricos estudados, foram: (i) um motor de 220,8 kW (300 cv) e (ii) três motores de $184 \mathrm{~kW}(250 \mathrm{cv})$.

O sistema de bombeamento EP1 se compõe de quatro conjuntos de motobombas ligados em paralelo, sendo que o quarto de reserva, acionados de maneira progressiva em função do número de irrigantes que estão demandando água simultaneamente. O primeiro conjunto motobomba é acionado automaticamente por um controlador lógico programável - CLP; um pressostato acoplado à parede interna da tubulação de recalque, envia informações quanto à pressão da rede de distribuição, as quais controlam um variador hidrocinético, para manter a pressão no eixo da bomba que, por sua vez, permite que o primeiro conjunto motobomba atenda de 1 a 20 irrigantes. Caso o número de irrigantes aumente, o sistema acionará a segunda bomba, que acolherá mais 13 irrigantes e, por último, o terceiro conjunto, que suprirá os 14 lotes restantes, em regime de utilização alternada dos conjuntos motobombas.

Os dados técnicos gerais da estação de bombeamento EP1, são: área irrigável do perímetro da EP1 de 255,32 ha e vazão de projeto de $1.265 \mathrm{~m}^{3} \mathrm{~h}^{-1}$, projetando uma dotação de irrigação de $1,37 \mathrm{~L} \mathrm{~s}^{-1} \mathrm{ha}^{-1}$. Para uma altura manométrica de $980 \mathrm{kPa}$ (100 mca), a potência requerida para os motores elétricos é de $772,8 \mathrm{~kW}(1050 \mathrm{cv})$ que projeta, para cada hectare irrigado, o uso em média de $3,03 \mathrm{~kW}$ (ou $4,1 \mathrm{cv}$ ) e a potência instalada total é de $1.500 \mathrm{kVA}$, com dois transformadores de $750 \mathrm{kVA}$. A Tabela 2 mostra as características dos motores da EP1.

Tabela 2. Características dos motores da estação de pressurização-EP1

\begin{tabular}{lcccc}
\hline \multirow{2}{*}{ Discriminação } & \multicolumn{4}{c}{ Estação de Pressurização 1 } \\
\cline { 2 - 6 } & Motor 1 & Motor 2 & Motor 3 & Motor 4 \\
\hline Fabricante & WEG & WEG & WEG & WEG \\
Modelo & HFG 315 A & 315 S/M & 315 S/M & 315 S/M \\
Número de fases & 3 & 3 & 3 & 3 \\
Número de pólos & 4 & 4 & 4 & 4 \\
Potência (kW) & 220,8 & 184 & 184 & 184 \\
$\begin{array}{l}\text { Tensão (V) } \\
\text { Horas de funcionamento } \\
\left.\text { (h ano }{ }^{-1}\right)^{*}\end{array}$ & 380 & 380 & 380 & 380 \\
* Funcionamento praticado no perímetro irrigado $^{2}$ & 3.540 & 1.100 & 900 & 800 \\
\hline
\end{tabular}

* Funcionamento praticado no perímetro irrigado

\section{Proposta para dimensionamento elétrico}

Para adequação de força motriz, é conveniente que se faça a avaliação do índice de carregamento e do rendimento do motor na condição de carga atual (Teixeira et al., 2001; Teixeira, 2002). A avaliação do índice de carregamento foi feita por

Tabela 1. Características das bombas da estação de pressurização 1

\begin{tabular}{ccccccc}
\hline Bomba & $\begin{array}{c}\text { Fabricante - KSB } \\
\text { Modelo }\end{array}$ & $\begin{array}{c}\text { Vazão } \\
\left(\mathrm{m}^{3} \mathrm{~h}^{-1}\right)\end{array}$ & $\begin{array}{c}\text { Altura Manométrica } \\
(\mathrm{kPa})\end{array}$ & $\begin{array}{c}\text { Número de } \\
\text { Estágios }\end{array}$ & $\begin{array}{c}\text { Rotor } \\
(\mathrm{mm})\end{array}$ & $\begin{array}{c}\text { Rotação } \\
(\mathrm{rpm})\end{array}$ \\
\hline $1^{* *}$ & ETA $-150-50$ & 411 & 980 & 1 & 480 & 1750 \\
$1^{* *}$ & ETA-150-50 & 500 & 980 & 1 & 480 & 1750 \\
2 & ETA-150-50 & 300 & 980 & 1 & 462 & 1750 \\
3 & ETA- $-150-50$ & 300 & 980 & 1 & 462 & 1750 \\
4 & ETA $-150-50$ & 300 & 980 & 1 & 462 & 1750 \\
\hline
\end{tabular}

* Características de projeto; ** Características praticadas. Fonte: KSB, s/d 
estimativa da carga mecânica e a determinação do rendimento via medição da corrente elétrica, por ser a mais simples (Sá et al., 1990). Para medição da corrente elétrica dos motores, utilizou-se um amperímetro alicate.

Em todos os equipamentos estudados, a corrente elétrica medida foi aquela referente ao regime normal de trabalho da estação de pressurização 1 . De posse das correntes elétricas do motor trabalhando em plena carga, e de seus dados de placa, determinou-se o índice de carregamento $\left(\mathrm{I}_{\mathrm{c}}\right)$ e a potência fornecida em relação à nominal, por meio da curva característica de corrente (Figura 2). Com o I ${ }_{c}$, foi determinado o rendimento por meio da curva característica (WEG, 2000).

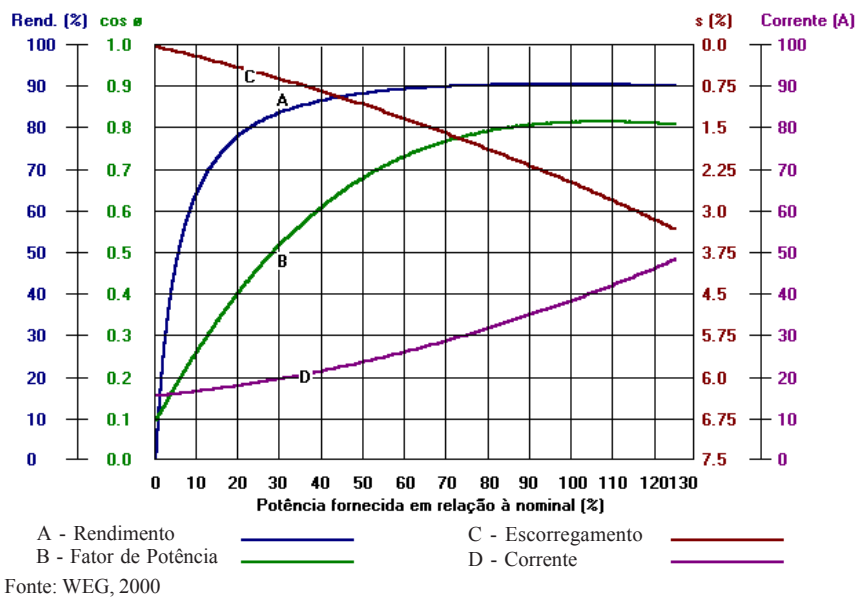

Figura 2. Curva característica típica de motor elétrico

As opções para adequação do uso de força motriz, que foram estudadas:

a) Motor padrão (PD) em uso versus motor novo de mesma potência de alto rendimento (AR);

b) Motor (PD) em uso versus motor (AR) novo, adequado à condição de carga;

c) Motor (PD) em uso versus motor (PD) em uso, adequado à condição de carga.

\section{Análise da técnica de gerenciamento do uso atual de água}

No Projeto de Irrigação de Mirorós optou-se, como forma de fornecimento de água aos irrigantes, pela adoção de hidrantes próprios, em que não há restrição do uso da água em nenhum momento do ano. Como não há restrição ao uso de água, pode ocorrer baixo carregamento do motor e da bomba, durante muitas horas no ano; sabe-se, porém, que a utilização desordenada de água pode aumentar o consumo de energia elétrica, haja vista que os rendimentos hidráulico e elétrico são função do carregamento dos equipamentos.

\section{Proposta para técnica de gerenciamento do uso de água}

A utilização do sistema de irrigação por parte de somente um irrigante, ou de vários irrigantes ao mesmo tempo, propicia a ineficiência ou eficiência dos conjuntos motobombas, as quais são funções do rendimento e do índice de carregamento dos motores elétricos.

Observa-se que, para diminuir o consumo de energia elétrica, ocorrerão algumas mudanças no comportamento dos irrigantes. A irrigação deve ser feita de forma a concentrar o maior número de irrigantes para maximização do rendimento e do índice de carregamento do conjunto motobomba. Nota-se que o consumo de água, em $\mathrm{m}^{3}$ ano $^{-1}$, para o fornecimento de um lote agrícola, é diferente do consumo de vários lotes funcionando simultaneamente, resultando numa diferença no rendimento do sistema.

O consumo de energia do sistema já implantado pode ser estimado pela equação.

$$
E=\frac{t_{c} p n I_{c}}{\eta}
$$

em que:

$$
\begin{array}{ll}
\mathrm{E} & \text { - gasto com energia elétrica, } \mathrm{R} \$ \mathrm{ano}^{-1} \\
\mathrm{t}_{\mathrm{c}} & \text { - tarifa de consumo, } \mathrm{R} \$ \mathrm{kWh}^{-1} \\
\mathrm{p} & \text { - potência nominal do motor, } \mathrm{kW} \\
\mathrm{n} & \text { - número de horas de funcionamento anual } \\
\mathrm{I}_{\mathrm{C}} & \text { - índice de carregamento, } \% \\
\eta & \text { - rendimento do motor elétrico, } \%
\end{array}
$$

\section{Análise econômica}

Para cada situação foram analisados os dados de entrada da análise econômica, tais como: número de horas de funcionamento anual, vida útil, taxa de juros, aumento da energia acima da inflação no horizonte de planejamento, preço do consumo e demanda no horário-de-ponta e fora-de-ponta, preço dos motores e manutenção, dentre outros. $\mathrm{Na}$ análise econômica da racionalização do uso de força motriz foram utilizados, como parâmetros econômicos, a taxa interna de retorno (TIR), valor presente líquido (VPL), relação benefício/ custo (RBC) e taxa de retorno do capital (TRC) (Frizzone \& Silveira, 2000).

\section{RESULTADOS E DISCUSSÃO}

\section{Adequação de bombas centrífugas}

De acordo com a Tabela 1, pode-se fazer a simulação e verificação das especificações técnicas dos conjuntos motobombas pelo programa computacional Agribombas (Santos, 2000; Santos, 2001). Pelas características do conjunto motobomba 1 da EP1 para vazão nominal de $411 \mathrm{~m}^{3} \mathrm{~h}^{-1} \mathrm{e}$ para altura manométrica de $980 \mathrm{kPa}$ (100 mca), verificou-se que a primeira sugestão de opção de troca do conjunto motobomba 1, seria a substituição do conjunto KSB, modelo ETA - 150-50, pelo conjunto Mark Peerless, modelo DN 150-50, com a adoção de um motor de 147,2 kW (200 cv) ao invés de um motor de 220,8 kW (300 cv) que atenderá às condições especificadas de forma otimizada, com uma economia de $3,6 \%$; a segunda opção possível seria a substituição por um conjunto motobomba ITA 150 -500, com a adoção de um motor de 147,2 kW (200 cv) ao invés de um motor de $220,8 \mathrm{~kW}(300 \mathrm{cv})$, para atender às condições especificadas de forma otimizada, com um ganho de rendimento de $0,7 \%$.

Ainda para o conjunto motobomba 1 da EP1 para vazão de trabalho atual $500 \mathrm{~m}^{3} \mathrm{~h}^{-1} \mathrm{e}$ para altura manométrica de $980 \mathrm{kPa}$ (100 mca), constatou-se que, para o conjunto motobomba 1 , seria indicada a substituição do conjunto KSB modelo ETA 150-50, pelo conjunto Mark Peerless, modelo DN 150-50, com a adoção de um motor de $184 \mathrm{~kW}(250 \mathrm{cv})$ ao invés de um motor de 220,8 kW (300 cv) que atenderia às condições especificadas de forma otimizada, com uma economia de 2,5\%. 
Em ambas as situações, a possibilidade do ganho de rendimento no conjunto motobomba só foi possível devido a escolha do conjunto motobomba ser feita de forma digital e não manual e que houve, também, um grande avanço no processo de fabricação dos conjuntos motobombas, tornandoos mais eficientes pela adoção de novos materiais mecânicos e elétricos, no sentido de exigir menor corrente da rede para gerar a mesma potência no eixo do conjunto motobomba.

A Tabela 3 apresenta os dados referentes à simulação de troca do conjunto motobomba para as condições especificadas de vazão e altura manométrica.

De acordo com a Tabela 3, constatou-se que, para a vazão de $300 \mathrm{~m}^{3} \mathrm{~h}^{-1}$ e altura manométrica de $980 \mathrm{kPa}(100 \mathrm{mca})$, a primeira sugestão de opção de troca do conjunto motobomba 2 seria a substituição do conjunto KSB modelo ETA-150-50, pelo conjunto EH modelo EHF-100 - 25. Neste caso, a adoção de um motor de 110,4 kW (150 cv) ao invés de um motor de 184 $\mathrm{kW}(250 \mathrm{cv})$, atenderia às condições especificadas de forma otimizada, com uma economia de $19,14 \%$.

Este potencial de economia $(19,14 \%)$ só é possível de ser conseguido devido ao aumento de eficiência do conjunto motobomba que está disponível no mercado hoje, o que não acontecia há 30 anos, aproximadamente, quando o conjunto motobomba KSB, modelo ETA 150-50, estava no auge da tecnologia desenvolvida até então.

\section{Adequação de força motriz}

A Tabela 4 mostra as correntes elétricas médias das fases feitas no perímetro irrigado, para os motores dos conjuntos motobomba 1 e 2, em função da vazão de serviço; ela foi elaborada em função de se acrescentar a vazão de serviço em $25 \mathrm{~m}^{3} \mathrm{~h}^{-1}$, que corresponde às necessidades de cada um dos irrigantes. Percebe-se, pela análise desta tabela, que: (i) as correntes das três fases dos motores estão perfeitamente equilibradas; (ii) uma variação máxima na corrente do motor 1 de $180 \mathrm{~A}$ até $340 \mathrm{~A}$; (iii) que a entrada do motor 2 diminui a corrente no motor 1 , de 340 para 220 A por fase, diminuindo o seu índice de carregamento, e (iv) no segundo conjunto motobomba as correntes se mantêm iguais, porque não possuem um variador de vazão, como o existente no conjunto 1 .

A Tabela 5 contém os dados dos índices econômicos utilizados para a realização da análise econômica dos dois motores elétricos estudados, e nela foram descritas as informações necessárias para a realização da análise econômica dos
Tabela 4. Corrente de dois motores da estação de pressurização -EP1, do perímetro irrigado de Mirorós

\begin{tabular}{|c|c|c|c|}
\hline \multirow{2}{*}{$\begin{array}{l}\text { Número de Lotes } \\
\text { Irrigando } \\
\text { Simultaneamente }\end{array}$} & \multirow{2}{*}{$\begin{array}{c}\text { Vazão de } \\
\text { Serviço }\left(\mathrm{m}^{3} \mathrm{~h}^{-1}\right)\end{array}$} & \multicolumn{2}{|c|}{ Motor $1 \quad$ Motor 2} \\
\hline & & Corrente & Média (A) \\
\hline 01 & 25 & 180 & \\
\hline 03 & 75 & 190 & \\
\hline 05 & 125 & 200 & \\
\hline 07 & 175 & 220 & \\
\hline 09 & 225 & 225 & \\
\hline 11 & 275 & 250 & \\
\hline 13 & 325 & 270 & \\
\hline 15 & 375 & 290 & \\
\hline 17 & 425 & 315 & \\
\hline 19 & 475 & 330 & \\
\hline 20 & 500 & 340 & \\
\hline 21 & 525 & 220 & 255 \\
\hline 23 & 575 & 240 & 260 \\
\hline 25 & 625 & 260 & 260 \\
\hline 27 & 675 & 280 & 260 \\
\hline 29 & 725 & 300 & 260 \\
\hline 31 & 775 & 320 & 260 \\
\hline 33 & 825 & 340 & 270 \\
\hline
\end{tabular}

Tabela 5. Levantamento de dados para realização de análise econômica de motores elétricos da estação de pressurização 1, do perímetro irrigado de Mirorós

\begin{tabular}{|c|c|c|}
\hline Discriminação & Unidade & $\begin{array}{l}\text { Motor Padrão ou } \\
\text { Alto Rendimento }\end{array}$ \\
\hline Potência & $\mathrm{kW}(\mathrm{cv})$ & $220,8$ a 184 (300 a 250$)$ \\
\hline Índice de carregamento & $\%$ & 30 a 90 \\
\hline Rendimento & $\%$ & 50 a 95 \\
\hline Preço do motor & $\mathrm{R} \$$ & $9.000,00$ a $15.000,00$ \\
\hline $\begin{array}{l}\mathrm{N}^{\mathrm{o}} \text { de horas de funcionamento } \\
\text { anual maximizado }\end{array}$ & $\mathrm{H}$ & entre 2.800 e 3.540 \\
\hline Juros & $\%$ ano $^{-1}$ & 8 \\
\hline $\begin{array}{l}\text { Valor de sucata no ano final } \\
\text { da vida útil }\end{array}$ & $\%$ do novo & 20 \\
\hline Custo unitário da energia* & $\mathrm{R} \$ \mathrm{kWh}^{-1}$ & 0,04936 \\
\hline Custo unitário da demanda* & $\mathrm{R} \$ \mathrm{~kW}^{-1}$ & 5,949 \\
\hline $\begin{array}{l}\text { Aumento do preço da energia } \\
\text { acima da inflação }\end{array}$ & $\%$ ano $^{-1}$ & 2 \\
\hline Manutenção & $\%$ & 1 \\
\hline Horizonte de planejamento & Ano & 10 \\
\hline
\end{tabular}

motores elétricos, para melhor opção de troca, tais como: preço do motor, taxa de atratividade de investimento, número de horas de funcionamento anual, rendimento e índice de carregamento a plena carga, dentre outras.

Tabela 3. Características do conjunto motobomba 2 da EP1 para vazão nominal de $300 \mathrm{~m}^{3} \mathrm{~h}^{-1} \mathrm{e} \mathrm{para}$ altura manométrica de $980 \mathrm{kPa}(100 \mathrm{mca})$

\begin{tabular}{lccccc}
\hline \multirow{2}{*}{ Descrição } & \multirow{2}{*}{ Situação Atual } & \multicolumn{4}{c}{ Situação Recomendada } \\
\cline { 3 - 6 } & & $1^{\mathrm{a}}$ Opção & $2^{\mathrm{a}}$ Opção & $3^{\text {a }}$ Opção & $4^{\mathrm{a}}$ Opção \\
\hline Fabricante & KSB & EH & KSB & M. Peerless & IMBIL \\
Modelo & ETA $-150-50$ & EHF $100-25$ & Megan $80-250$ & DN 150-50 & ITA 150.500 \\
Vazão $\left(\mathrm{m}^{3} \mathrm{~h}^{-1}\right)$ & 300 & 300 & 300 & 300 & 300 \\
Altura manométrica $(\mathrm{kPa})$ & 980 & 980 & 980 & 980 & 980 \\
Rotor $(\mathrm{mm})$ & 462 & 266 & 462 & 480 & 480 \\
Rotação (rpm) & 1750 & 3500 & 3500 & 1750 & 1780 \\
Potência exigida do motor $(\mathrm{kW})$ & $184(250 \mathrm{cv})$ & $110,4(150)$ & $128,8(175)$ & $128,8(175)$ & $128,8(175)$ \\
Número de estágios & 1 & 1 & 1 & 1 & 1 \\
Rendimento da bomba (\%) & 70,5 & 81,5 & 72,1 & 71,0 & 70,3 \\
Ganho de rendimento $(\%)$ & & 19,14 & 3,1 & 1,0 & $-0,4$ \\
\hline
\end{tabular}


Com as correntes elétricas medidas e as informações nominais dos motores elétricos, tais como tipo de motor, rotação, potência e horário de funcionamento diário, dentre outros, em conjunto com os índices econômicos, pôde-se realizar a análise econômica de vida útil no horizonte de planejamento.

A análise econômica com a opção mais vantajosa de troca entre os motores analisados de 220,8 kW (300 cv) tipo HGF 315 A, seria a substituição por um motor de HGF 315 A de 198,72 $\mathrm{kW}(270 \mathrm{cv})$ do ponto de vista técnico, mas, do ponto de vista econômico, não é viável a substituição; portanto, não seria recomendável a substituição do motor de $220,8 \mathrm{~kW}$ por esta avaliação. Os resultados de aplicação da metodologia para adequação de força motriz, são apresentados na Tabela 6 , para o motor estudado.

De acordo com a Tabela 6, para o motor de $184 \mathrm{~kW}(250 \mathrm{cv})$ do conjunto motobomba 2, como primeira opção de troca de motores dentre todas as alternativas estudadas seria a substituição do motor padrão atual de $184 \mathrm{~kW}(250 \mathrm{cv})$ com I de $80,00 \%$, por um motor de alto rendimento adequado à condição de carga de 184,00 kW (250 cv) com I de 80\%. Logo, a economia anual seria de $2,77 \%$ ( $R \$ 1.030,59)$. Os parâmetros econômicos para esta situação, seriam: VPL de R\$ 4.608,53, TIR de $45 \%$, RBC de 2,24 vezes e TRC de 2 anos e 2 meses, reforçariam a tomada de decisão.

Analisando-se os dois motores elétricos e se utilizando sempre a melhor opção de troca de motores elétricos, observouse que o potencial total estimado de economia de energia elétrica anual foi de cerca de 3\%, representando R $\$ 1.030,59$.

A adoção de motores de alto rendimento e a adequação de força motriz proporcionam um grande potencial de economia de energia elétrica. A permanência de motores tipo standard e a falta do controle da corrente dos motores em funcionamento com a carga de trabalho, levam a uma eficiência menor do sistema. A forma tradicional de se dimensionar e conduzir o funcionamento dos motores elétricos, leva a situações de superdimensionamento e desperdício de energia elétrica.

É necessário frisar que a economia aqui descrita se refere apenas à adequação do uso de motores elétricos. A possível redução de demanda advinda do uso adequado de bombas hidráulicas e do sistema de irrigação foi descrita anteriormente.

A Tabela 7 apresenta a análise do potencial de economia de energia global com adequação do conjunto motobomba 1 , da EP1 e, de acordo com ela, a economia anual com gastos de energia elétrica pode chegar a $8,75 \%(\mathrm{R} \$ 2.975,86)$ comparandose o conjunto atual (motor de $300 \mathrm{cv}$ e bomba com vazão de 500 $\mathrm{m}^{3} \mathrm{~h}^{-1}$ ) com o conjunto proposto (motor de $250 \mathrm{cv}$ e bomba de $500 \mathrm{~m}^{3} \mathrm{~h}^{-1}$ ) que apresenta melhor desempenho entre o motor e a bomba.

A Tabela 8 mostra a análise do potencial de economia de energia global com adequação do conjunto motobomba 2 , da EP1.

Conforme a Tabela 8 , a economia anual com gastos de energia elétrica pode chegar a $31,6 \%(\mathrm{R} \$ 6.741,39)$ comparando-se o conjunto atual (motor de $250 \mathrm{cv}$ e bomba com vazão de 300 $\mathrm{m}^{3} \mathrm{~h}^{-1}$ ) com o conjunto proposto (motor de $150 \mathrm{cv}$ e bomba de $300 \mathrm{~m}^{3} \mathrm{~h}^{-1}$ ) que apresenta o melhor desempenho entre o motor e a bomba.

Para o cálculo da otimização, foram utilizados os valores das correntes medidas nos motores no local e, ainda, que, quando utilizados os dados de vazão, altura manométrica e rendimento da bomba pelo catálogo do fabricante, pode-se atribuir a diferença dos resultados: (i) à escolha do rotor, que não corresponde ao de maior rendimento; (ii) à rede elétrica, se desbalanceada; (iii) ao nível de tensão, se estiver oscilando; e (iv) às diferenças entre as curvas características nominais da bomba e motor, como indicam os fabricantes.

Tabela 6. Análise econômica com a opção mais vantajosa de troca entre os motores analisados para o motor de $184 \mathrm{~kW}(250 \mathrm{cv})$ para melhor opção de troca

\begin{tabular}{|c|c|c|c|}
\hline \multicolumn{4}{|c|}{ Motor de $184 \mathrm{~kW}(250 \mathrm{cv})$} \\
\hline Item & & Motor PD & Motor AR - AD \\
\hline Potência & $\mathrm{kW}(\mathrm{cv})$ & $184(250)$ & $184(250)$ \\
\hline Número de horas & $\left(\mathrm{h}\right.$ ano $\left.^{-1}\right)$ & 2.800 & 2.800 \\
\hline Carga & $\%$ & 80,00 & 80,00 \\
\hline Rendimento & $\%$ & 92,82 & 95,79 \\
\hline Consumo de energia elétrica & $\mathrm{kWh}$ ano $^{-1}$ & $\mathrm{R} \$ 21.917,92$ & $\mathrm{R} \$ 21.238,35$ \\
\hline Demanda de energia elétrica & $\mathrm{kW}$ ano $^{-1}$ & $\mathrm{R} \$ 11.321,17$ & $\mathrm{R} \$ 10.970,16$ \\
\hline Conta de energia & $\mathrm{R} \$ \mathrm{ano}^{-1}$ & $\mathrm{R} \$ 33.239,10$ & $\mathrm{R} \$ 32.208,51$ \\
\hline Preço do motor & $\mathrm{R} \$$ & $9.789,00$ & $14.879,19$ \\
\hline \multirow[t]{2}{*}{ Economia anual com energia elétrica $(\mathrm{R} \$)$} & & \multicolumn{2}{|c|}{$\mathrm{R} \$ 1.030,59(2,77 \%)$} \\
\hline & \multicolumn{3}{|c|}{ Análise econômica dos motores } \\
\hline Motores & PD & $\mathrm{PD} A D$ & AR-AD \\
\hline $\mathrm{VP}\left(\mathrm{R} \$ \mathrm{kWh}^{-1}\right)$ & 0,053 & 0,053 & 0,054 \\
\hline Índices econômicos & \multicolumn{3}{|c|}{ Comparação econômica } \\
\hline & $\mathrm{PD}$ com $\mathrm{PD} A D$ & PD com AR & PD com AR AD \\
\hline VPL (R\$) & $\mathrm{R} \$ 2.470,10$ & $\mathrm{R} \$ 2.195,94$ & $\mathrm{R} \$ 4.608,53$ \\
\hline TIR (\% aa) & não converge & $16 \%$ & $45 \%$ \\
\hline $\mathrm{RBC}$ (decimal) & 1,65 & 0,43 & 2,24 \\
\hline TRC (ano) & Imediato & 4 anos e 4 meses & 2 anos e 2 meses \\
\hline
\end{tabular}

* PD - motor padrão; PD AD - motor padrão adequado à condição de carga; $\mathrm{AR}$ - motor de alto rendimento; $\mathrm{AR} \mathrm{AD}$ - motor de alto rendimento adequado à condição de carga; $\mathrm{AR} \mathrm{AD} / \mathrm{h}$ - motor de alto rendimento adequado à condição de carga, com otimização do número de horas de funcionamento anual; TIR - taxa interna de retorno; VPL - valor presente líquido; RBC - relação benefício custo; TRC - tempo de retorno do capital 
Tabela 7. Análise do potencial de economia de energia global com adequação do conjunto motobomba 1, da EP1

\begin{tabular}{lccc} 
Discriminação & Situação Atual & Situação Projetada & Situação Otimizada \\
\hline Potência exigida do motor $(\mathrm{kW})$ & $220,80(300 \mathrm{cv})$ & $220,80(300 \mathrm{cv})$ & $184(250 \mathrm{cv})$ \\
Tipo de motor elétrico & Alto Rendimento & Alto Rendimento & Alto Rendimento \\
Vazão da bomba $\left(\mathrm{m}^{3} \mathrm{~h}^{-1}\right)$ & 500 & 500 & 500 \\
Altura manométrica $(\mathrm{kPa})$ & $980(100 \mathrm{mca})$ & $980(100 \mathrm{mca})$ & $980(100 \mathrm{mca})$ \\
Rotações por minuto $(\mathrm{rpm})$ & 1.750 & 1.750 & 1.750 \\
Horas de funcionamento anual & 3.540 & 3.540 & 3.540 \\
Índice de carregamento $(\%)$ & 83,00 & 78,63 & 92,5 \\
Rendimento do motor $(\%)$ & 94,14 & 94,14 & 95,79 \\
Rendimento da bomba $(\%)$ & 78,50 & 78,50 & 80,10 \\
Valor do consumo de energia $\left(\mathrm{R} \$ \mathrm{kWh}^{-1}\right)$ & 0,04936 & 0,04936 & 0,04936 \\
Consumo de energia elétrica $\left(\mathrm{kWh} \mathrm{ano}{ }^{-1}\right)$ & $689.138,05$ & $652.895,19$ & $628.831,99$ \\
Gasto com consumo de energia elétrica $\left(\mathrm{R} \$\right.$ ano $\left.^{-1}\right)$ & $34.015,85$ & $32.226,91$ & $31.039,99$ \\
Economia $(\%)$ & - & - & 8,75
\end{tabular}

Tabela 8. Análise do potencial de economia de energia global com adequação do conjunto motobomba 2, da EP1

\begin{tabular}{lccc} 
Descrição & Situação Atual & Situação Projetada & Situação Otimizada \\
\hline Potência do motor $(\mathrm{kW})$ & $184(250 \mathrm{cv})$ & $184(250 \mathrm{cv})$ & $110,4(150 \mathrm{cv})$ \\
Tipo de motor elétrico & Padrão & Padrão & Alto Rendimento \\
Vazão da bomba $\left(\mathrm{m}^{3} \mathrm{~h}^{-1}\right)$ & 300 & 300 & 300 \\
Altura manométrica $(\mathrm{kPa})$ & $980(100 \mathrm{mca})$ & $980(100 \mathrm{mca})$ & $980(100 \mathrm{mca})$ \\
Rotações por minuto $(\mathrm{rpm})$ & 1.750 & 1.750 & 3.500 \\
Horas de funcionamento anual & 2.800 & 2.800 & 2.800 \\
Índice de carregamento $(\%)$ & 78,0 & 63,0 & 90,9 \\
Rendimento do motor $(\%)$ & 92,82 & 92,19 & 94,8 \\
Rendimento da bomba $(\%)$ & 70,50 & 70,50 & 81,50 \\
Valor do consumo de energia $\left(\mathrm{R} \$ \mathrm{kWh}^{-1}\right)$ & 0,04936 & 0,04936 & 0,04936 \\
Consumo de energia elétrica $\left(\mathrm{kWh} \mathrm{ano}^{-1}\right)$ & $432.941,18$ & $352.306,30$ & $296.365,33$ \\
Gasto com consumo de energia elétrica $\left(\mathrm{R} \$\right.$ ano $\left.^{-1}\right)$ & $21.369,98$ & $17.389,84$ & $14.628,59$ \\
Economia $(\%)$ & - & - & 31,6 \\
\hline
\end{tabular}

\section{Técnica de gerenciamento do uso da água}

Atualmente, a gerência do Distrito de Irrigação do Perímetro Irrigado de Mirorós (DIPIM) tem requerido, junto aos associados, uma posição da CODEVASF, órgão do governo federal, em resolver questões de infra-estrutura operacional do projeto e a responsabilidade de solucioná-lo tecnicamente. Uma das discussões mais relevantes é o valor da conta de energia, que todo mês é agregado ao preço do produto agrícola, tornando desfavorável a sua competição no mercado. Devido a isto, seus associados pagavam uma tarifa de $\mathrm{R} \$ 28,43$ por cada $1.000 \mathrm{~m}^{3}$ consumidos em sua lavoura, calculada considerandose a conta de energia, e mais $\mathrm{R} \$ 8,22 \mathrm{ha}^{-1}$ irrigado referentes a outros encargos do projeto; com isto, o Perímetro Irrigado de Mirorós tem uma das tarifas de irrigação mais caras do Vale do São Francisco.

O comportamento dos irrigantes em relação ao uso da água tem que ser levado em conta, pois o objetivo final é servir os associados no momento em que a lavoura exigir água, utilizandose corretamente o período de irrigação. Tanto os dimensionamentos da irrigação como o bombeamento da água e potência dos motores, deverão ser acompanhados de gerenciamento que visem à racionalização de energia.

Observou-se, pela forma da utilização de água dos irrigantes, que a eficiência do sistema é dependente do número de lotes irrigados simultaneamente. A Tabela 9 apresenta, por meio de seus dados, o preço diferenciado de $1.000 \mathrm{~m}^{3}$ de água, em função do número de irrigantes.

Para o cálculo desta tabela, consideraram-se os seguintes dados:
- tarifa aplicada de consumo é de $\mathrm{R} \$ 0,04936 \mathrm{~kW}^{-1}$

- potência no conjunto 1 é de $220,8 \mathrm{~kW}(300 \mathrm{cv})$ e para o conjunto 2 é de $184 \mathrm{~kW}(250 \mathrm{cv})$

- horas de funcionamento anual previsto para o conjunto 1 é de $3.540 \mathrm{~h}$ e para o conjunto 2 é de $2.800 \mathrm{~h}$

- a vazão permitida para os lotes é de $24,88 \mathrm{~m}^{3} \mathrm{~h}^{-1}$.

Analisando-se a Tabela 9, percebe-se diminuição no valor da água com o aumento do número de lotes funcionando e, ainda, que, quando entra em funcionamento a segunda motobomba no lote 21 , ocorre aumento no preço da água em relação ao aumento do número de irrigantes concluindo-se que, quando a segunda motobomba entra funcionando para levar água a treze lotes, a primeira motobomba reduz para oito lotes, aumentando progressivamente através do variador hidrocinético, conforme o aumento da demanda de água.

De acordo com os resultados da Tabela 9, quando apenas 1 irrigante utiliza o sistema de bombeamento de água, o preço é de $\mathrm{R} \$ 163,31\left(1000 \mathrm{~m}^{-3}\right)$; já quando o número de irrigantes for maior, por exemplo igual a 15 , o custo do sistema de bombeamento da água cairá para $\mathrm{R} \$ 21,79\left(1.000 \mathrm{~m}^{-3}\right)$, ou seja, quanto maior for o número de lotes irrigados simultaneamente, menor será o valor do $\mathrm{R} \$\left(1.000 \mathrm{~m}^{-3}\right)$ (Fig. 3). foram:

As principais indicações de racionalização do uso de energia

1. Para o motor de $220,8 \mathrm{~kW}(300,0 \mathrm{cv})$ do conjunto motobomba 1, pela adequação de força motriz, tecnicamente seria melhor a substituição por um motor de HGF 315 A de 198,7 kW (270,0 cv) mas, economicamente, não é viável a substituição; 
Tabela 9. Custo da energia para cada situação de carga, do conjunto motobomba 1 e 2

\begin{tabular}{|c|c|c|c|c|c|c|c|}
\hline \multicolumn{8}{|c|}{ Conjunto Motobomba 1 e 2} \\
\hline \multirow{2}{*}{$\begin{array}{l}\mathrm{N}^{\mathrm{o}} \text { de Lotes } \\
\text { Funcionando }\end{array}$} & \multicolumn{2}{|c|}{ Índice de Carga (\%) } & \multicolumn{2}{|c|}{ Rendimento (\%) } & \multirow{2}{*}{$\begin{array}{c}\mathrm{E} \\
\mathrm{R} \$ \mathrm{ano}^{-1}\end{array}$} & \multirow{2}{*}{$\begin{array}{l}\text { Volume } \\
\text { Bombeado } \\
\mathrm{m}^{3} \text { ano }^{-1}\end{array}$} & \multirow{2}{*}{$\begin{array}{c}\text { Valor } \\
\mathrm{R} \$(1.000)^{-1} \mathrm{~m}^{-}\end{array}$} \\
\hline & $220,8 \mathrm{~kW}$ & $184 \mathrm{~kW}$ & $220,8 \mathrm{~kW}$ & $184 \mathrm{~kW}$ & & & \\
\hline 1 & 34 & & 91,2 & & $14.383,40$ & 88.075 & 163,31 \\
\hline 3 & 37 & & 91,5 & & $15.601,20$ & 264.225 & 59,05 \\
\hline 5 & 42 & & 92,2 & & $17.575,02$ & 440.376 & 39,91 \\
\hline 7 & 50 & & 92,8 & & $20.787,37$ & 616.526 & 33,72 \\
\hline 9 & 51 & & 92,8 & & $21.203,12$ & 792.676 & 26,75 \\
\hline 11 & 58 & & 93,5 & & $23.932,82$ & 968.827 & 24,70 \\
\hline 13 & 65 & & 93,8 & & $26.735,48$ & 1.144 .977 & 23,35 \\
\hline 15 & 70 & & 93,8 & & $28.792,06$ & 1.321 .128 & 21,79 \\
\hline 17 & 76 & & 94,1 & & $31.160,29$ & 1.497 .278 & 20,81 \\
\hline 19 & 81 & & 94,1 & & $33.210,31$ & 1.673 .428 & 19,85 \\
\hline 20 & 82 & & 94,1 & & $33.620,31$ & 1.761 .504 & 19,09 \\
\hline 21 & 48 & 73 & 92,2 & 92,5 & $40.155,04$ & 1.610 .233 & 24,94 \\
\hline 23 & 55 & 75 & 93,2 & 92,5 & $43.387,11$ & 1.786 .384 & 24,29 \\
\hline 25 & 62 & 75 & 93,5 & 92,5 & $46.202,50$ & 1.962 .534 & 23,54 \\
\hline 27 & 66 & 75 & 93,8 & 92,5 & $47.765,94$ & 2.138 .684 & 22,33 \\
\hline 29 & 73 & 75 & 93,8 & 92,5 & $50.645,14$ & 2.314 .835 & 21,88 \\
\hline 31 & 78 & 75 & 94,1 & 92,5 & $52.599,43$ & 2.490 .985 & 21,12 \\
\hline 33 & 82 & 78 & 94,1 & 92,8 & $54.994,89$ & 2.667 .136 & 20,62 \\
\hline
\end{tabular}

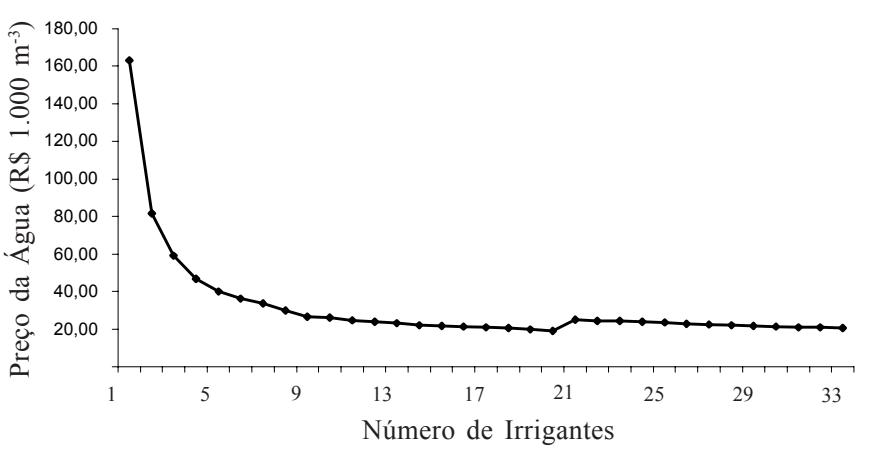

Figura 3. Preço da água no perímetro irrigado, considerando-se apenas o custo do consumo de energia elétrica em função do número de irrigantes que estão operando simultaneamente

2. Para o motor de $184,0 \mathrm{~kW}(250,0 \mathrm{cv})$ do conjunto motobomba 2, como é indicado, a substituição do motor padrão atual de $184,0 \mathrm{~kW}(250,0 \mathrm{cv})$ com I de $80,0 \%$, por um motor de alto rendimento, é adequado à condição de carga de 184,0 kW (250,0 cv) com I de 80,0\%, por esta avaliação; logo, a economia anual seria de $3,0 \%$, representando $\mathrm{R} \$ 1.030,59$ por ano;

3. O conjunto motobomba 1 sugerido para substituir o conjunto KSB modelo ETA - 50-50, é o conjunto Mark Peerless, modelo DN 150-50, com a adoção de um motor de 147,2 kW (200 cv) ao invés de um motor de $220,8 \mathrm{~kW}$ (300,0 cv), que atenderia às condições especificadas de forma otimizada, com rendimento de $79,7 \%$, para a vazão nominal de $411 \mathrm{~m}^{3} \mathrm{~h}^{-1}$;

4. O conjunto motobomba 2, sugerido para substituir o conjunto KSB modelo ETA - 150-50 pelo conjunto motobomba Mark Peerless, modelo DN 150-50, com a adoção de um motor de $128,8 \mathrm{~kW}(175 \mathrm{cv})$ ao invés de um motor de $184,0 \mathrm{~kW}$ $(250,0 \mathrm{cv})$, atenderia às condições especificadas, com rendimento de $71,0 \%$;

5. O potencial de economia de energia global com a adequação do conjunto motobomba 1 foi de cerca de $8,75 \%$;
6. O potencial de economia de energia global com a adequação do conjunto motobomba 2 foi de cerca de $31,6 \%$. Recomenda-se revisar a otimização hidráulica e elétrica (dimensionamento de bombas e motores) haja vista a ampliação em cerca de $41 \%$ do horário de desconto, na tarifa para irrigação (das 21:30 h às 6:00 h);

7. Observou-se que, quando apenas um irrigante utiliza o sistema de bombeamento de água, o preço é de $\mathrm{R} \$ 163,31$ por $1000 \mathrm{~m}^{3}$; agora, quando o número de irrigantes for maior, por exemplo igual a 15 , o custo do sistema de bombeamento da água cairá para $\mathrm{R} \$ 21,79$ por $1000 \mathrm{~m}^{-3}$, ou seja, quanto maior for o número de lotes irrigados simultaneamente, menor será o valor do $\mathrm{R} \$ 1000 \mathrm{~m}^{-3}$. A utilização maximizada da operação do bombeamento de água o é como forma de se minimizar o custo do bombeamento de água em função do número de irrigantes;

8. De acordo com o exposto, o potencial de economia anual de energia pode variar de 3 a $32 \%$ e o ganho de rendimento percentual no uso de energia, entre 3 a $19 \%$.

\section{CONCLUSÕES}

1. Este artigo apresenta técnicas para realização de racionalização energética em perímetros irrigados e em estações de bombeamento, em geral. O patamar de economia de energia encontrado, $31,6 \%$, é significativo e mostra, assim, a importância do estudo de racionalização.

2. Demonstrou-se que se deve considerar, de forma integrada, os aspectos de adequação de força motriz, dimensionamento hidráulico, especialmente a adequação das bombas e o manejo do uso de água com avaliação econômica de vida útil, para que se maximize a economia.

\section{AGRADECIMENTOS}

Os autores agradecem ao Gerente Executivo do Distrito de Irrigação do Perímetro Irrigado de Mirorós, Eng ${ }^{\circ}$ Agrônomo 
Paulo Henrique de Araújo, pela liberação das informações necessárias. Ao chefe de Operação e Manutenção do DIPIM e sua equipe, Sr. Isaías Neri Santana, pela disposição, acompanhamento e apoio na aquisição dos dados. Enfim, ao Departamento de Operação e Manutenção da CODEVASF em Brasília, DF, que apoiou a iniciativa do trabalho.

\section{LITERATURA CITADA}

Bernardo, S. Manual de irrigação. 6 ed. Viçosa: Universidade Federal de Viçosa, Imprensa Universitária, 1995. 657p.

Campana, S. Racionalização do uso de energia elétrica em sistemas de irrigação tipos pivô central e aspersão convencional. Viçosa: Universidade Federal de Viçosa, 2000. 108p. Dissertação Mestrado

Christofidis, D. Irrigação, a fronteira hídrica na produção de alimentos. Irrigação e Tecnologia Moderna - ITEM/Associação Brasileira de Irrigação e Drenagem - ABID, Brasília, n.54, 2002.76p.

Frizzone, J.A.; Silveira, S. de F.R. Avaliação e custos de projetos de irrigação. In: Seminário Energia na Agricultura, 1, 2000, Uberaba. Anais...Uberaba: Companhia Energética de Minas Gerais, 2000.p.280.

KSB, Bombas hidráulicas S.A. Manual técnico e curvas características série ETA. Várzea Paulista, SP. s/d. 30p
Sá, J.S.; Cogo, J.R.; Arango, H. Avaliação do rendimento de motores de indução trifásica via medição de tensão e corrente no estator. In: Seminário Internacional de Distribuição de Energia Elétrica, 1, 1990, Belo Horizonte. Resumos... Belo Horizonte: Companhia Energética de Minas Gerais, 1990. v.1. 3.

Santos, J.R.M. dos. Irrigar é preciso. Agroanalysis. Rio de Janeiro: Fundação Getúlio Vargas - FGV. n³ 3, 1998. p. 29-34

Santos, W.L. Agribombas - Programa racional para seleção de bombas agrícolas, Universidade Federal de Viçosa (UFV), 2000. Disponível via URL: www.ufv.br.

Santos, W.L. Desenvolvimento de uma metodologia para representação analítica de curvas características de bombas hidráulicas, visando à sua seleção, seu dimensionamento e a simulação de sua operação. Viçosa: Universidade Federal de Viçosa, 2001. 69p. Tese Doutorado

Teixeira, C.A. Metodologia para adequação do uso de força motriz em processos agrícolas. Viçosa: Universidade Federal de Viçosa, 2002. 155p. Dissertação Mestrado

Teixeira, C.A.; Oliveira Filho, D.; Lacerda Filho, A.F. Racionalização do uso de força motriz em fábrica de ração da Universidade Federal de Viçosa - Estudo de caso. In: Seminário de Energia na Agricultura - Indicando Novos Caminhos para a Produtividade no Campo, 2, 2001. Uberaba. Anais... Uberaba: Companhia Energética de Minas Gerais, 2001. p.64-74.

WEG, Catálogo eletrônico 2000. Jaraguá do Sul (http:// www.weg.com.br), Data da consulta: 01/08/2002. 